\title{
STRESS INCONTINENCE
}

\author{
By John Beattie, M.D., F.R.C.S., F.R.C.O.G. \\ Gynaecological Surgeon, St. Bartholomew's Hospital
}

So far the mist has cleared very little from around this difficult subject despite the original work which has been carried out during the last 10 years. Operations for the cure of stress incontinence have been described from time to time during the last 50 years, but until recently most gynaecologists considered that a modified anterior colporrhaphy was all that was necessary to achieve a lasting cure.

One of the most important things in dealing with this subject is first to differentiate true stress incontinence from inability to control the passage of urine from the bladder when the urge to micturate becomes great. There is also the leak which occurs in retention with overflow to consider and other conditions which cause weakness of the bladder sphincter without a true stress incontinence being present.

Some women suffer from stress incontinence which is superimposed upon an abnormality of bladder function which was present in childhood due to a congenital cause. A recent investigation of 40 patients operated upon for stress incontinence at St. Bartholomew's Hospital showed that the following abnormalities of bladder function had occurred during childhood: enuresis, 8 per cent.; urge incontinence, 12 per cent.; excessive frequency, ro per cent. Some of these symptoms were combined in a single case and an abnormality of function of the bladder in childhood occurred in 10 of the 40 cases ( 25 per cent.).

These figures may be compared with those of Fisher and Forsythe ${ }^{1}$ who found in 135 children over the age of 5 ( $5 \mathrm{I}$ were girls) 20 cases of abnormal bladder, i.e. three neurogenic disorders, I4 with wide bladder neck anomaly and three with a small capacity bladder. Vesical spasm also may occur in children without infection when a small capacity bladder is present due to a failure of physiological development. This condition can continue into adult life or may develop after the menopause due to shrinkage of bladder capacity with consequent frequency and urgency of micturition.

Abnurmal bladder symptoms in children may persist into adult life and it is most important to obtain such a history, otherwise a patient may be operated upon for urethrocele when the symptoms are due to something else or if true stress incontinence develops after child bearing in such a patient the results of operation may be disappointing.

Other abnormalities of bladder function which must be differentiated from a case of true stress incontinence are as follows:

\section{The Neurogenic Bladder}

The bladder is often a most sensitive indicator of neurological disease and, of course, there may be, and often is, vaginal prolapse present at the onset of such a condition. The most often quoted instance of the neurogenic bladder is disseminated sclerosis, and, indeed, it is the commonest neurological disorder found in the British Isles. The early symptoms may cause a temporary disturbance of function only and of short duration. The more common type exhibits acute exacerbations at intervals with quiescent phases lasting for up to seven years or more. The gynaecologist should look out for the following stigmata of the disease in all cases complaining of defective bladder function, for in disseminated sclerosis there may be urgency and precipitancy with urge incontinence and, less commonly, retention with overflow. There may be also defective memory, disturbances of sensation, scanning speech, dragging of the foot, horizontal nystagmus, diplopia or temporary loss or dimness of vision and emotional disturbances which are often diagnosed as hysteria. There may be pain and stiffness with weakness of one or both legs, especially when tired, an increase in the deep reflexes, loss of the abdominal reflex and an extensor plantar response, a spastic gait and intention tremor.

If any case of stress incontinence exhibits one or more of these symptoms and signs, the patient should be referred for an expert neurological opinion.

Other neurological conditions which may simulate a mechanical stress incontinence are neurosyphilis and compression of the cord or corda equina due to tumours or other lesions. Abnormal 


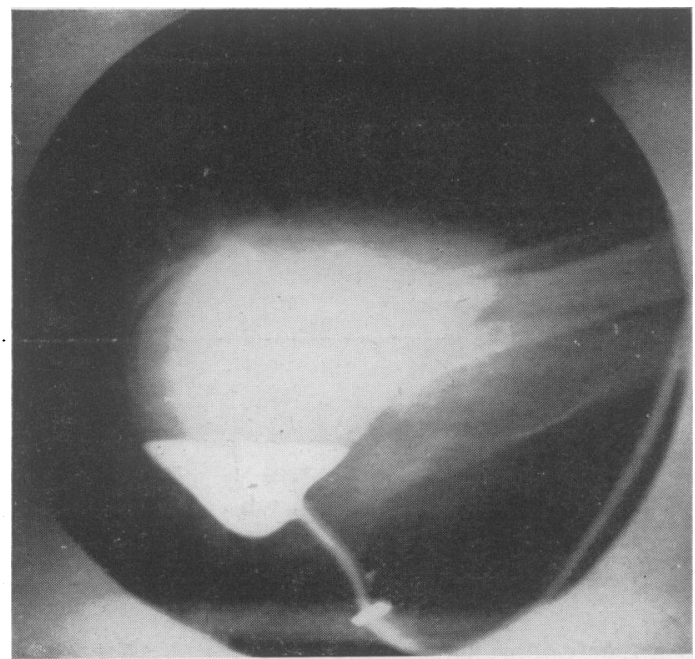

Straining cystogram. Posterior urethro-vesical angle present.

bladder function may also occur as a hysterical manifestation. The symptoms produced by diabetes insipidus have been diagnosed as due to prolapse owing to the vast quantities of urine passed, which caused frequency and urge incontinence in a multipara. The tabetic bladder dysfunction may antedate the Argyll-Robertson pupil and absent knee jerks. In these cases there is an imbalance between the sympathetic and parasympathetic nerve supply with retention of urine, overflow and incontinence.

\section{The Psychogenic Bladder}

The psychogenic bladder is probably the most interesting of all, for a functional element may produce frequency, urgency, urge incontinence or stress incontinence at any time even after a successful operation for the cure of urethrocele has been performed.

The writer had a recent example of this in a woman who for 18 months complained of stress incontinence which was demonstrated during a vaginal examination. There was no urethrocele present and a straining cystogram showed a well marked posterior urethro-vesical angle and no funnelling of the internal meatus. The urine was sterile. The symptoms began after an emotional upset over her daughter. In view of all the negative findings the patient was reassured and given a bottle of potassium citrate mixture. This cured her completely but an operation would also have been a success !

It is important therefore to differentiate the case of true stress incontinence from those mentioned above. A typical case is easy to diagnose, for the

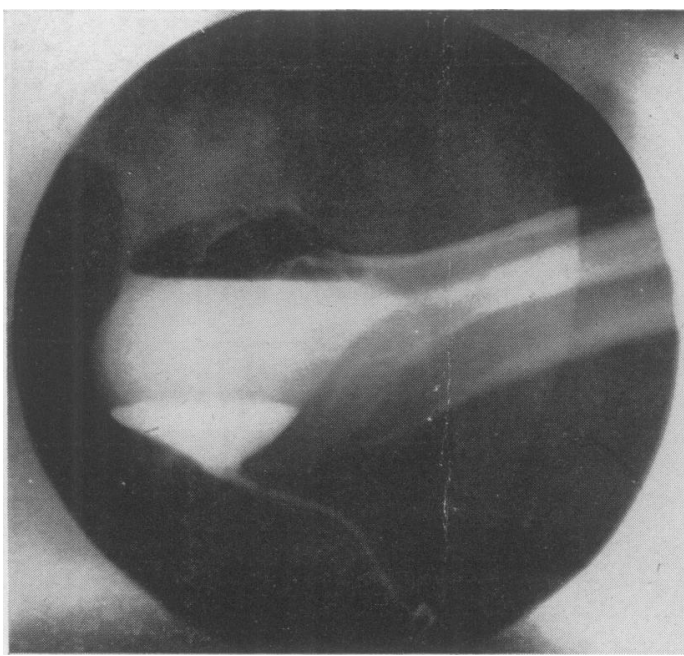

Straining cystogram. Posterior urethro-vesical angle or is absent.

stress incontinence occurs only on exertion, $\vec{z}$ whether standing or sitting. It is customary to

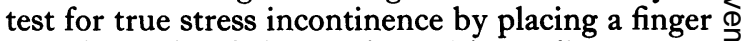
to either side of the urethra without direct cone pression upon it. The incontinence on stress should then be cured when the urethra is thut $\overrightarrow{0}$ supported. A useful test is the application of a Hodge pessary in the reversed position when the narrow end lies above the symphysis pubis and this reconstitutes the absent urethro-vesical angle which will produce a temporary cure of the stress incontinence.

In some patients with stress incontinence, $\overrightarrow{\vec{P}}$ particularly in the rather rare case of the nul- $\frac{0}{3}$ lipara, it is not possible to demonstrate the physical signs of urethral prolapse. These are the cases which present considerable difficulty and in which a straining cystogram is required. It is 3 . remarkable also that a severe degree of vaginal $\dot{\sigma}$ prolapse may be present without stress incon- 3 . tinence and with a well marked urethro-vesical $\delta$ angle which persists when straining. Stress incontinence may on rare occasions occur when urethral funnelling is present and also herniation of the trigone.

Jeffcoate and Robinson ${ }^{2}$ have proved con- N clusively in many hundreds of X-ray photographs that in at least 90 per cent. of all cases of true stress incontinence the posterior urethro-vesical $\omega$ angle is absent when straining, and is also often absent when the bladder is at rest (Figs. I and 2). This investigation therefore in the great majority of $\Phi$ cases gives a clear indication of the necessity or $\stackrel{?}{?}$ otherwise of operation to cure a case of stress 
incontinence. The angle normally varies between $90^{\circ}$ and $130^{\circ}$.

The anatomy of bladder function has been a controversial subject for many years but it now seems clear that the following structures take part in the act of micturition.

I. The inner circular and outer longitudinal muscle fibres of the bladder mingle at the urethral orifice to form a double sling. These fibres continue down the urethral wall towards the triangular ligament. This constitutes the main sphincter which remains closed except during micturition.

2. The membranous sphincter or compressor urethrae extends above the triangular ligament and embraces the urethra. The muscle fibres pass to the lateral walls of the vagina and up to the bladder base. This structure produces the main voluntary control of micturition.

3. The Levator Ani muscle. Contrary to previous statements it now seems to be proven that the pubo-coccygeus does not send fibres to embrace the urethra but these are inserted laterally into the vaginal wall and when contracted they pull the urethra up and forward to compress it.

4. The vesico-vaginal fascia is a muscle sheet which also contains elastic tissue which spreads round and to either side of the urethra and to the vaginal wall.

5. The bulbo cavernosus surrounds the lower end of the vagina and connects between the urethra and the clitoris by a dense band of fibrous tissue. When the bulbo cavernosus contracts it will draw the urethra towards the anus and thus compress it against the anterior vaginal wall and against the levator ani muscle which contracts at the same time and compresses the urethra in the opposite direction.

The last four structures mentioned when put into action will produce voluntary cessation of micturition when necessary. This second line of defence is efficient enough to allow $5^{\circ}$ per cent. of women with stress incontinence to stop the leak with ease if they are conscious of the risk when a sudden stress is about to occur. Cinematograph films taken during the act of micturition show that when this ceases by voluntary effort, the compressor urethrae cuts off the flow and the urethra then empties backwards into the bladder (Ardran, Simmons and Stewart ${ }^{3}$.

The physiology of bladder function is obscure, but certain proven facts are now established. When the bladder fills slowly, as it does normally, there is almost no increase in muscle tone and under these conditions the pressure in the bladder varies between zero and ro c.c. of water. The involuntary sphincter control is an efficient mechanism under these circumstances and all that is necessary is to have a mechanism to resist an increase of pressure which occurs on exertion. When the bladder contains 250 c.c. of urine there is an urge to micturate, which is easily controlled and which then passes off while the bladder continues to fill slowly. When about 500 c.c. is present in the bladder a further and more powerful urge to micturate occurs. Superimposed upon this normal bladder mechanism is the influence of the will and there is probably no function in the body which is more directly under control in this way.

The act of micturition is initiated by various reflexes and voluntary control is destroyed by section of the nervi erigentes, which contain both afferent and efferent paths. It is the pressure in the bladder and not the volume which starts the act and the normal pressure required varies between 40 and 90 c.c. of water. This sudden rise of pressure relaxes the internal meatus and at the same time there is relaxation of the levator ani and a coincident slight voluntary increase in intraabdominal pressure. When the pressure of urine in the urethra rises to between 3 and ${ }_{5} 5$ c.c. of water further contraction of the detrusor of the bladder occurs.

During the act of micturition pressure starts at 30 to 50 c.c. of water and can rise to 50 or 100 c.c. by voluntary expulsive efforts. When coughing with a full bladder the intravesical pressure can rise as high as 100 c.c. of water with complete continence in the normal subject. The voluntary muscles of urethral control under these circumstances play an important role in maintaining continence. It is notable, therefore, that in cases of acquired stress incontinence the single abnormality, apart from the rare abnormalities such as funnelling and trigone hernia, is absence of the urethro-vesical angle on straining. In this respect the changes which occur in the bladder during the first and second stages of labour, as described by Malpas and Jeffcote ${ }^{4}$, are of great interest. The level of the bladder base in the pelvis is not altered during the first stage of labour. As the presenting part descends in the second stage the urethrovesical junction moves towards the symphysis pubis. The extent of the displacement of the bladder and urethra depends on the relative sizes of the presenting part and the cavity of the pelvis. If there is delay due to a tight fit in the plane of the mid cavity, the bladder neck may be lifted to the top of the symphysis pubis and the bladder is rolled upwards and forwards. In view of this the old theory that the urethra is pushed off the symphysis pubis is untenable. The rotation of the bladder must stretch the lower pole and the investment surrounding the posterior wall of the bladder neck. In this way obliteration of the urethro-vesical 
angle occurs just as in stress incontinence and it is common to see involuntary voiding of urine under stress during the descent of the head in the second stage of labour.

The obliteration of the posterior urethro-vesical angle must be associated with stretching or damage to the urethral supports and those of the bladder base, but a recent paper by Youssef and Mahfouz ${ }^{5}$ suggests that in cases of stress incontinence there is also an actual acquired weakness of the urethral sphincter. It may be, therefore, that the obliteration of the urethro-vesical angle is associated with loss of tone in the intrinsic involuntary musculature of the bladder neck.

The successful cure of stress incontinence is still hard to achieve. $\mathrm{Kegel}^{6}$ is a great exponent of the conservative approach to the subject and he has published good results in both the nullipara and the multipara by using the vaginal obturator connected to a perineometer. Constant exercise of the levator ani muscle upon the obturator increases the tone and strengthens the vesico-vaginal fascia.

Until recent years most gynaecologists considered that a modified anterior colporrhaphy for stress incontinence was all that was required to produce a permanent cure. Indeed, the operation was often left to the house surgeon, whereas to produce a good result requires experience and considerable technical skill. Whatever special sutures may be employed to bring together and plicate the vesico- and urethro-vaginal fascia the principles remain the same. A wide dissection of the urethra and bladder base must be achieved without any remaining adhesion to the anterior vaginal wall. The attachments of the pubococcygeus muscles to the sulci lateral to the urethra and in the anterior vaginal wall must be exposed. A wide plication of the urethro-vaginal fascia is then carried out by means of Lembert's sutures, using fine chromicized catgut. The bladder itself should not be unduly plicated above the vesicourethral junction, as this may tend to obliterate the posterior angle. The same complication will occur if the anterior vaginal wall is shortened by a continuous suture which is drawn tight. It is a major disaster to find that a patient who has had a Manchester repair performed for uterine and vaginal prolapse has developed stress incontinence in consequence because the anterior vaginal wall has been shortened. Modifications of this technique with descriptions of special sutures have been described by Kelly, Pacey, Reddington, Ingleman Sundberg and others.

A permanent cure of stress incontinence cannot be assessed until more than two years have elapsed since operation. In expert hands the success of local suture of the urethral supports varies between 75 and 90 per cent. Jeffcote has published some interesting results of straining cystograms taken after the cure of 30 cases of stress incontinence by $z$ the ordinary method. Only in four of these was $\stackrel{\varnothing}{\complement}$ the urethro-vesical angle restored, showing that $C$ the reconstitution of the angle by this form of $\vec{F}$ operation is extremely difficult to achieve. In nine $\stackrel{0}{+}$ of the 30 cases stress incontinence subsequently $\frac{}{}$ recurred and the success in the other patients must $\frac{\bar{\sigma}}{\bar{\omega}}$. have been due entirely to a strengthening of the $\frac{\sigma}{\sigma}$ voluntary supports of the urethra.

When stress incontinence recurs after a col- œ porrhaphy has been performed it is possible to $\overrightarrow{0}$ repeat the same operation, but with only moderate success in curing the symptoms. Most gynae- $\vec{\omega}$ cologists will resort to some other form of opera- $\frac{\rho}{\circ}$ tion, of which the placing of a sling under the urethra to lift it forwards and upwards and thus reconstitute the urethro-vesical angle is the most popular. Giordano in 1907 first used the gracilis muscle for this purpose and Goebell in rgro used $\omega$ the pyramidalis muscle by transplantation. Stoekel 걱 in 1917 used strips of rectus muscle to place around the urethra and did an anterior colporrhaphy as 을 well. Aldridge ${ }^{7}$ then made the sling operation $\vec{z}$ popular once more by using strips of fascia of the external oblique muscles to pass round the urethra $₫$ and be sewn together beneath it through an ing 3 cision in the anterior vaginal wall. This is still the safest and most reliable of all modern sling operâ $\overrightarrow{0}$ tions, but it is laborious to perform and time con ज़ suming. Millin and $\operatorname{Read}^{8}$ have described two sling operations and the second one includes the use of fascia lata to place beneath the urethra and through the rectus muscles and fascia in the suprapubic region. Some surgeons use wide nylon ribbon, which is introduced around the urethra in the same way.

All sling operations produce an excellent result if they are performed with great care by a really skilled gynaecologist who is well used to vaginal surgery. In order to achieve a good result the $\bar{\partial}$ following criteria must be satisfied. It is necessary to find the line of cleavage between bladder fascia and vaginal skin. After free mobilization of the bladder a modified anterior colporrhaphy, as done to cure stress incontinence, is first performed and the sling is then adjusted under the urethra at the 의 correct tension so that the urethro-vesical angle is $D$ reconstituted. It is wise to leave the bladder with $8 \mathrm{oz}$. of water in it for a few hours to produce $\bar{N}$ pressure against the dead space on each side of $O$ the bladder base through which the sling has been $\tilde{S}$ introduced.

The dangers and complications of any sling operation may be considerable and are nearly all 0 associated with the sling being tied too tight and producing an excessive angulation of the urethra. In this way it is possible to produce vesical or 0 


\title{
$A$ book for the postgraduate
}

\section{Practical Obstetric Problems}

\section{by IAN DONALD}

M.B.E., M.D. (Lond.), F.R.C.O.G.

Regius Professor of Midwifery, University of Glasgow

"There is no better concise yet reasonable statement of the modern practice of obstetrics." Brit. Med. J.

"... this book is likely to become the standby of the obstetric practitioner and especially of the aspirant for higher degrees, for it presents a well-balanced account of modern obstetric practice." J. Obstet. Gynaec. Brit. Emp.

$x i i+578 p p$. 115 illustrations (1955) 47s. 6d. net

\section{A new monograph}

\section{Anaesthetic Accidents}

\author{
by V. KeAting
}

M.B., B.Ch., D.A., F.F.A. R.C.S.

Consultant Anaesthetist and Lecturer in Anaesthetics,

University College Hospital of the West Indies

This work correlates current opinion on the prevention, diagnosis and treatment of the immediate and remote complications of general and regional anaesthesia, with each section of the book illustrated by the author's personal observations. Anaesthetic accidents are relatively uncommon, but when they do occur they may lead to the death or life-long invalidism of the patient; thus a knowledge of the experience of others and pertinent experimental facts are important.

vii +261 pp. 13 illustrations (1956) 25s. net

\section{Lloyd-Luke (Medical Books) Ltd., 49, Newman Street, W.I}

urethral fistulae, partial or complete obstruction of the urethra, chronic over-distension of the bladder, avulsion of the urethra, loss of the micturition reflex and persistent infection of the urinary bladder. Haematomata around the bladder and infection in the retropubic space may also occur.

As a sling operation is done as a rule only after a previous operation has failed to cure stress incontinence, the surgeon tends to pull the sling too tight, as he dare not fail to cure the condition by allowing it to be too loose. Efforts are being made at present to devise some means of measuring the tension required in individual cases, which varies with the resistance produced when the urethra is lifted upwards and forwards.

There is little doubt that whatever method of sling operation is performed the final result is produced by fibrosis around the operation area, which keeps the urethra in its new position. In cases in which the sling has had to be removed owing to suppuration around it the ultimate result is usually as good as if the sling was still in place.

In this respect it is interesting that good results are claimed both by Mulvaney, ${ }^{9}$ who frees the bladder base and urethra through a suprapubic extra-peritoneal incision and does nothing else, and by Everard Williams, ${ }^{10}$ and by Marshall
Marchetti and Krantz, ${ }^{11}$ who recommend a freeing of the urethra and bladder base in the same way followed by suture of the urethra, bladder base or lateral vaginal fornices to the periosteum behind the pubic bones, thus lifting up the urethra and reconstituting the posterior urethro-vesical angle.

This brief résumé of the modern operative treatment of stress incontinence demonstrates clearly that the problem has not yet been solved and will not be so until more is known of the dysfunction of the bladder which occurs in cases of stress incontinence.

\section{REFERENCES}

I. FISHER, O. D., and FORSYTHE, W. I. (1954), Archives o Dis. in Children, Oct., $46 \mathrm{r}$.

2. JEFFCOTE, T. N. A., and ROBERTS, H. (1952), f. Obstet. Gynaec. Brit. Emp., 59, 685.

3. ARDRAN, G. M., SIMMONS, G. A., and STEWART, J. H. (1956), Ibid.; 63, 26.

4. MAIPAS, P., and JEFFCOTE, T. N. A. (1949), Ibid., 56, $940^{\circ}$ 5. YOUSSEF, A. F., and MAHFOUZ, M. M. (1956), Ibid., 63, I9.

6. KEGEL, A. H. (1951), f. Amer. med. Ass., 146, 9.

7. ALDRIDGE, H. (1942), Amer. F. Obstet. \& Gynec., 44, 398.

8. MILLIN, T., and READ, C. (1948), Postgrad. med. F., 24, 268.

9. MULVANEY, J. H. (1952), f. Obstet. Gynaec. Brit. Emp., 59, 7 II.

ro. WILliaMS, E. (1946), Proc. R.S.M., 40, 36r.

II. MARSHALL, V. F., MARCHETTI, A. A., and KRANTZ. K. E. (1949), Surg. Gynec. Obstet., 88, 509.' 